\title{
PEDAGOGY
}

\section{ИСПОЛЬЗОВАНИЕ АЛГОРИТМА ПОСТРОЕНИЯ ДЕФИНИЦИИ В РАМКАХ ТЕРМОДИНАМИЧЕСКОГО ПОДХОДА К ОПИСАНИЮ ХИМИЧЕСКИХ РЕАКЦИЙ}

Профессор Бердзенишвили И. Г.

Грузия, Тбилиси, Грузинский технический университет

DOI: https://doi.org/10.31435/rsglobal_wos/31082019/6656

\section{ARTICLE INFO}

Received: 14 June 2019

Accepted: 05 August 2019

Published: 31 August 2019

\section{KEYWORDS}

thermodynamic approach, chemical reaction, algorithm, definition, isobaric potential.

\begin{abstract}
The article deals with the thermodynamic approach for describing chemical processes and phenomena. It is shown that the Gibbs energy minimization method is successfully used to assess the possibility of a spontaneous reaction in isobaric-isothermal conditions. The author analyzes ways to implement this thermodynamic method for studying chemical processes. In order to disclose the content of a scientific concept "isobaric potential of formation of a substance", an algorithm for constructing this definition is proposed, which is based on detailing of all its components.
\end{abstract}

Citation: Бердзенишвили И. Г. (2019) Ispol'zovanie Algoritma Postroeniya Definicii v Ramkah Termodinamicheskogo Podhoda k Opisaniyu Himicheskih Reakcij. International Academy Journal Web of Scholar. 8(38), Vol.2. doi: 10.31435/rsglobal_wos/31082019/6656

Copyright: (C) 2019 Бердзенишвили И. Г. This is an open-access article distributed under the terms of the Creative Commons Attribution License (CC BY). The use, distribution or reproduction in other forums is permitted, provided the original author(s) or licensor are credited and that the original publication in this journal is cited, in accordance with accepted academic practice. No use, distribution or reproduction is permitted which does not comply with these terms.

Введение. С химической термодинамикой знакомятся студенты почти всех технических специальностей. Основной целью изучения данной дисциплины является ознакомление студентов с принципами использования термодинамического подхода для описания химических процессов и явлений. Предсказание направления и глубины протекания процессов в системе - одна из главнейших задач химической термодинамики [1-3].

Для оценки принципиальной возможности/ невозможности протекания химических взаимодействий достаточно использовать метод минимизации энергии Гиббса, т.е. достаточно рассчитать изменение энергии Гиббса (также свободная энергия Гиббса, потенциал Гиббса, изобарный потенциал или изобарно-изотермический потенциал, $\Delta G_{p, T}$ или упрощенно $\left.\Delta G\right)$ в ходе реакции [3-5].

Учитывая, что большинство процессов осуществляются при $p=$ const и $T=$ const, в статье рассматриваются именно процессы, протекающие в изобарно-изотермических условиях.

Отметим, что свободная энергия Гиббса является «движущей силой» химической реакции, протекающей в изобарно-изотермических условиях, критерием же принципиальной возможности самопроизвольного протекания такой реакции является ее убывание, т.е. $\Delta G_{p, T}<0$ [1-5].

Результаты исследований. Для определения термодинамической вероятности протекания процесса в заданном направлении, студенты должны владеть навыками расчета стандартных энергий Гиббса (стандартных значений потенциала Гиббса) химических реакций.

Расчет осуществляется двумя способами. Первый способ расчета базируется на том, что на протекание химического процесса влияют два фактора: энтальпийный $(\Delta H)$ и энтропийный 
$(T \Delta S)$. Совместное действие этих двух факторов в процессах, протекающих при постоянных $p$ и $T$, и определяет потенциал Гиббса реакционной системы $[1-3,6]$ :

$$
\Delta G=\Delta H-T \Delta S .
$$

Стандартная энергия Гиббса реакции $\left(\Delta G^{0}\right)$ при $298 K$ рассчитывается по уравнению:

$$
\Delta G^{0}=\Delta H^{0}-298 \Delta S^{0} \text {. }
$$

Отметим, что данный расчет следует начать с определения изменения энтальпии и энтропии реакции в стандартных условиях. Так как самопроизвольно химические реакции могут протекать только лишь в сторону убывания потенциала, то отрицательной энергии Гиббса реакционной системы будет отвечать уменьшение энтальпии $(\Delta H<0)$ и увеличение энтропии $(\Delta S>0)$. Если $\Delta H>0$ и $\Delta S<0$, то реакция невозможна.

Второй способ расчета предусматривает использование величин изобарных потенциалов образования $\Delta_{f} G^{0}$ химических соединений (индекс $f$ значит formation - образование). В данном случае стандартная энергия Гиббса реакции определяется как разность двух сумм, взятых по изобарным потенциалам образования продуктов реакции и исходных компонентов.

Изобарные потенциалы образования простых веществ в устойчивых формах принимаются равными нулю $[1-3,5]$; отсчитывая $G$ участников реакции от уровня простых веществ получаем уравнение:

$$
\Delta G^{0}=\sum \Delta_{f} G^{0}{ }_{\text {прод. }}-\sum \Delta_{f} G^{0}{ }_{\text {ucx. }}
$$

Очевидно, что полученное значение $\Delta G^{0}$ позволит оценить насколько глубоко проходит процесс от исходных компонентов до конечных продуктов при постоянных $p$ и $T$.

Реализация навыков прогнозирования хода процесса предусматривает полное и точное понимание дефиниции (определения) изобарных потенциалов образования химических соединений, содержание которого нередко недостаточно четко осознается студентами, что затрудняет восприятие как самого определения, так и проведение термодинамических расчетов.

C целью раскрытия содержания данного научного понятия в помощь студентам мы предлагаем алгоритм построения данной дефиниции, который базируется на детализации всех составляющих ее компонентов.

Итак, чтобы можно было лучше понять содержание дефиниции, представленного термином

\begin{tabular}{|c|c|}
\hline Вопросы & Ответы \\
\hline Наименование понятия & Изобарный потенциал образования вещества \\
\hline $\begin{array}{l}\text { Обозначение } \quad \text { изобарного } \\
\text { образования вещества }\end{array}$ & $\Delta_{f} G^{0}$ \\
\hline $\begin{array}{l}\text { Что представляет собой изобарный потенциал } \\
\text { образования? }\end{array}$ & Изменение энергии Гиббса \\
\hline Изменение энергии Гиббса какой реакции? & Реакции образования данного вещества \\
\hline $\begin{array}{lcc}\text { Количество вещества, которое } & \text { должно } \\
\text { образоваться во время реакции } & \\
\end{array}$ & 1 моль \\
\hline $\begin{array}{l}\text { Состояние, в котором должно находиться } \\
\text { данное вещество }\end{array}$ & Стандартное состояние \\
\hline $\begin{array}{llll}\text { Из каких веществ } & \text { образуется данное } \\
\text { вещество } & & & \end{array}$ & Из простых веществ \\
\hline $\begin{array}{l}\text { Состояния, в котором должны находиться } \\
\text { участники реакции }\end{array}$ & Стандартные состояния \\
\hline
\end{tabular}
«изобарный потенциал образования вещества» следует ответить на следующие вопросы (табл. 1).

Таблица 1. Обзор составляющих алгоритма

Совокупность правильных ответов на все поставленные вопросы постепенно, шаг за шагом подводят студента к конструированию дефиниции. Таким образом получилось следующее определение: «Изобарный потенциал образования вещества $\left(\Delta_{f} G^{0}\right)$ есть изменение энергии 
Гиббса при образовании 1 моля данного вещества в его стандартном состоянии из простых веществ взятых в их стандартных состояниях».

После усвоения содержание данной дефиниции, студенты запросто вычисляют $\Delta G^{0}$ любой реакции без необходимости расчета энтальпийного и энтропийного факторов. Именно по этой причине величины изобарных потенциалов образования $\Delta_{f} G^{0}$ химических соединений весьма важны при решении основных термодинамических задач.

Выводы. Предложенный алгоритм построения дефиниции является весьма эффективным способом исследовать глубину научного понятия, представленного термином «изобарный потенциал образования вещества» и широко используемого при термодинамической оценке принципиальной возможности протекания химической реакции. Подобный подход можно использовать и для построения других дефиниций, относящихся к химической термодинамике.

\section{ЛИТЕРАТУРА}

1. Зарубин Д.П. Физическая химия. - М.:ИНФРА-М, 2017. - 474 с.

2. Горшков В.И., Кузнецов И.А. Основы физической химии. Изд. 3-е, М.: Бином. Лаборатория знаний, 2009. - $407 \mathrm{c}$.

3. I. Berdzenishvili. Thermochemical measurements. Tbilisi: Technical University, 2017. - 135 p.

4. Тиноко И., Зауэр К., Венг Дж., Паглиси Дж. Физическая химия. Принципы и применение в биологических науках. - М.: Техносфера, 2005. - 743 c.

5. Basic Chemical Thermodynamics. 5th Edition by E. Brian Smith. (April 8, 2004). - 166 p.

6. Калибабчук В.А., Грищенко Л.И., Галинская В.И., Гождзинский С.М. и др. Медицинская химия. К.: Медицина, 2008. - 399 с. 